\title{
LOS MITOS EN LA POESÍA DE CABALLERO BONALD
}

\author{
THE MYTHS ON CABALLERO BONALD`S POETRY
}

\author{
Julio NEIRA \\ Universidad Nacional de Educación a Distancia \\ jneira@flog.uned.es
}

Resumen: La literatura nace con el mito, en tanto relato de una cosmovisión, y especialmente la poesía se ha nutrido de la mitología en todo su desarrollo. En España ha sido así sobre todo en épocas como los siglos de Oro, en que las Metamorfosis de Ovidio tuvo una amplia repercusión. También la poesía española contemporánea presenta esta influencia, incluso en los periodos en que el realismo y la conciencia social eran predominantes. En este artículo se repasa minuciosamente la presencia continuada y abundante de los mitos en la poesía de José Manuel Caballero Bonald a lo largo de toda su trayectoria.

Palabras clave: Mitos griegos. Poesía española contemporánea. Caballero Bonald.

Abstract: Literature is born with myth, as a story of the cosmos, and poetry has been particularly linked to mythology along the years. In Spain, was mainly so in the Golden Age, when Ovid's Metamorphoses had a wide impact. Spanish contemporary poetry also has this influence, even in periods when realism and social consciousness were predominant. This paper closely studies the ample presence of the myths in the poetry of José 
Manuel Caballero Bonald.

Key Words: Greek mythology. Contemporary Spanish poetry. Caballero Bonald.

La presencia de la mitología como elemento sustancial de la literatura es un fenómeno bien conocido desde la Grecia clásica que se ha reproducido después en todos los tiempos y culturas; y la literatura española, a lo largo de toda su historia, no ha sido una excepción (Cristóbal, 2000). Por lo que a la poesía se refiere, se documenta ya en un sucinto repaso de los textos medievales (Libro de Aleixandre, Juan de Mena, Marqués de Santillana, Enrique de Villena, etc.), a partir de la recuperación y la divulgación de las Metamorfosis de Ovidio realizada por los renacentistas italianos, con Bocaccio a la cabeza. Pero es en la lírica de los siglos áureos, y también en su teatro, donde la mitología domina de un modo abrumador, bien mediante fábulas compendiadas en un trabajo clásico por José María de Cossío (1952), bien como campo metafórico explotado a conciencia por todos los poetas, con especial protagonismo de Francisco de Aldana, Luis de Góngora, el Conde de Villamediana, Lope de Vega, Francisco de Quevedo o Pedro Calderón. Esa preponderancia temática y referencial dejó su huella en los escritores tardo-barrocos y menos en los neoclásicos del siglo XVIII, para casi desaparecer en el XIX con el intimismo romántico y el realismo positivista; pero rebrota con fuerza en el modernismo finisecular recordemos la "Venus" de Rubén Darío y a inicios del siglo XX (López Férez, coord., 2010), y con mayor intensidad en la denominada Generación del 27 (Gerardo Diego, Jorge Guillén, Federico García Lorca, Rafael Alberti, etc.), cuyo legado clásico fue estudiado por Díaz de Revenga (2003). Poetas que recuperaron los mitos con una perspectiva vanguardista, degradadora y sarcástica (Neira, 2003).

El componente mitológico en la poesía contemporánea ha sido 
estudiado de modo muy fragmentario, bien a través de algunos mitos específicos, como los de Afrodita/Venus (Márquez, 1994; Ortega Garrido, 2011), Narciso (Ruiz Esteban, 1990; Luján Atienza, 2009), Penélope (Marina Sáez, 2001-2003; González Delgado, 2005; Payeras Grau, 2009), Ícaro (Puppo, 2006) u Orfeo (Fernández López y Mora de Frutos, 2004); bien en la obra de algunos poetas de la llamada Generación del 68 (Lanz, 2011) o novísimos (Moralejo Álvarez, 2010), como Guillermo Carnero y Antonio Colinas (Pujals Gesali y Rodríguez de la Flor, 1981) o Aníbal Núñez (Salgado, 2009) y otros posteriores (Arcaz Pozo, 2010); e incluso se ha establecido su papel como instrumento para la construcción de una nueva identidad de género en la poesía escrita por mujeres (Merino Madrid, 2015). Pero apenas se ha profundizado en la obra de los llamados poetas del medio siglo o generación del 50 Carlos Barral, Jaime Gil de Biedma, Ángel González, José Ángel Valente (Lacalle Ciordia, 2005; Aguirre Martínez, 2015), José Manuel Caballero Bonald, etc., en busca de la huella de ese componente mítico, tal vez porque la etapa consolidadora de este grupo, más o menos entre 1956 y 1964, basada en el realismo como estrategia de agitación poético-política, les ha connotado con tal intensidad que les descarta a priori como autores de influencia mitológica. Y, sin embargo, al menos el último de los citados, José Manuel Caballero Bonald (Jerez de la Frontera, 1926), ha tenido muy presente el relato mitológico como elemento fundamental de su creación a lo largo de toda trayectoria, desde Memorias de poco tiempo (1954), su segundo libro, a Desaprendizajes (2015), el último de poesía publicado hasta el momento.

\section{$* * *$}

En el caso de Caballero Bonald, su interés por los mitos como elemento antropológico nuclear en la creación poética vino precedido por el placer de la experiencia lectora de los relatos míticos, nacida a edad temprana, en el albur de la adolescencia. Y en ello debió de tener no poca influencia su estudio del latín en clases particulares al abandonar el 
séptimo curso de Bachillerato a mediados de 1944 (Neira, 2014: 62-63). La traducción de textos latinos, las Metamorfosis de Ovidio entre ellos, despertaría en el joven la misma decisiva inclinación a la literatura que el descubrimiento de la azarosa vida de José de Espronceda o la lectura de las novelas de aventuras que le regalaba su tía Isabela. Por eso es bastante frecuente la huella de clásicos latinos en su obra, incluso en títulos de poemas y en epígrafes, como evidencian el subtítulo y el lema de Lucrecio en su autobiografía poética: Entreguerras o De la naturaleza de las cosas (2011).

Su primer poema con mención mitológica es "Frontera de Narciso", el vanidoso hijo de la ninfa Liríope que se enamora de sí mismo al verse reflejado en la superficie del agua y, castigado por la diosa Némesis, acaba suicidándose al no poder conseguir el objeto de su amor. Se trata de uno de los mitos más tratados por la poesía y la pintura occidentales (Luján Atienza, 2009) como símbolo del egotismo, la autocomplacencia y, en términos literarios, del solipsismo temático, como en este texto, donde el personaje poético busca una pasión desconocida y perturbadora, consciente de que en realidad: "Interminablemente / la buscaré sabiendo que me busco a mí mismo" (Caballero Bonald, 2011:99). Muchos años después, en Laberinto de Fortuna (1984) volverá sobre este mito en el poema "Narciso de aguas turbias" para expresar el fundamental componente egoísta del amor físico clandestino: "Nadie se ama más a sí mismo que el que penetra en otro amparado en lo oscuro" (Caballero Bonald, 2011: 437). Y aún casi veinte años más tarde volverá sobre Narciso en un poema de Manual de infractores (2005) al que luego me referiré.

Su tercera obra fue el grupo de cuatro poemas sobre los principales géneros del flamenco, la soleá, la saeta, el martinete y la seguiriya, que publicó como separata de la revista Papeles de Son Armadans en 1956. Tomó su título, Anteo, del gigante mitológico hijo de Gea, la diosa tierra, que le daba su fuerza invencible al estar en contacto con ella. Ninguno mejor para expresar el carácter telúrico y primigenio de un arte con raíces tan hondas como el flamenco, que sin embargo puede morir si se desprende 
de ese sustrato primordial que le da su naturaleza. El titulo del a vuelve inado en el pueblo como el flamencocon ella. arata de último poema, "Tierra sobre tierra", y su última estrofa reafirman ese símbolo: "Canto no: tierra sobre la tierra, / sangre en la sangre, augurio / de la sabiduría más primaria, difusa / clarividencia germinal del sueño, / civilizada seguiriya indomable" (Caballero Bonald, 2011: 139); y ya en el anterior, "Oficio del hierro", se afirma que el martinete surge de la "mitológica fragua del corazón" (Caballero Bonald, 2011: 135).

Muchos años después, en Entreguerras (2012) reiterará los vínculos mitológicos del flamenco de un modo mucho más explícito al referirse al proceso depurativo llevado a cabo en el cante hondo a partir de los años setenta:

alguien ascendió entonces hasta las cumbreras de la mitología y alli se unió a la casta de los omnipotentes Anteo Casandra Dédalo [Ariadna $y$ alli excavó en la tierra que le asignó el oráculo hasta que oyó los lentos animales de la noche el roce hirsuto de la fronda y supo que era llegado el tiempo de acceder a la espesura prodigiosa de aquella melodía que estaba contagiándose de muchas clases de [bellezas mientras iba la voz abriéndose camino como un topo sollozante por las duras estoicas estancias de una casa de la ya que ya habian sido sagazmente excluidos impostores y párvulos (Caballero Bonald, 2012: 181-182)

Su cuarto libro, Las horas muertas (1959), contiene dos poemas con trasunto mitológico: "Cloto" y "Cráter del tiempo". En la mitología griega Cloto es una de las tres moiras, hijas de Zeus y Temis, la hilandera, que tiene a su cargo controlar la vida de las personas tejiéndola con su rueca. Como ella, el protagonista del poema cree hilar su propia vida equilibrando "memorias / y esperanzas [...] el botín / con la renuncia" (Caballero Bonald, 2011: 159). Acaba el texto con uno de los característicos 
finales paradójicos de Caballero Bonald: "Sólo es verdad / lo que aún no conozco", que advierte sobre el carácter ilusorio del recuerdo de lo vivido. Cloto volverá a la poesía de Caballero Bonald en dos ocasiones más: una en compañía de Narciso en Manual de infractores para recordar que la vida es frágil, pues pende del hilo que teje la moira (recordemos la frase hecha), e igual de frágil es la fidelidad, por lo que, como Narciso, es preciso un exigente diálogo consigo mismo para cuestionarse lo vivido ("sólo está a salvo / el que a sí mismo se incrimina", Caballero Bonald, 2011: 581). La otra presencia de Cloto se da en el poema de La noche no tiene paredes (2009) "Se llama Cloto", donde se avizora el final de la vida, de ese hilo que produce "la dulce / tejedora de sueños"; el quebranto de la salud por la mucha edad hace inminente la conciencia de que vivir es ir consumiendo la vida hacia la muerte: "la trama de la vida consiste en deshacerla" (Caballero Bonald, 2011: 749).

El segundo poema de referencias clásicas de Las horas muertas es "Cráter del tiempo" (Caballero Bonald, 2011: 193-195) que recupera experiencias prostibularias ("antro inmundo") y en el que convoca a varios personajes mitológicos: Ulises el viajero, otra vez Anteo ("el hijo / de la Tierra a quien canté / en noches incendiarias"), Osiris, el dios egipcio, y las musas Erato, de la poesía amorosa, y Melpómene, de la tragedia. Este procedimiento metaforizador de una realidad sórdida y poco edificante a través de elevados referentes mitológicos, dioses, héroes y musas, produce el mismo extrañamiento que el proceso contrario, la degradación de los mitos realizada por los poetas barrocos y los vanguardistas, y sirve con igual eficacia como contrapunto sarcástico para hacer aflorar los "turbios rudimentos de mi vida" con una voluntad autocrítica que siempre ha caracterizado al poeta.

Tras el paréntesis de realismo-crítico que supuso Pliegos de cordel (1963), dieciocho años después reencontraremos ese proceso metafórico en Descrédito del héroe (1977), libro que supuso un giro trascedente en la poética de nuestro autor. Así, en el poema "Renuevo de un ciclo alejandrino" (Caballero Bonald, 2011: 299-301) se presenta otro sórdido 
episodio prostibulario en una casa de postas cercana a Jerez, donde gozan jornaleros y otros viajeros de "la inerte muchacha / que vende al transeúnte su miseria”, a través de referentes míticos ("por rescatar el heroísmo / de una epopeya oculta en un tugurio, / pérfido rastro de sustituciones"): el río Guadalete se vincula al río Escamandro que bañaba Troya, el poeta se transfigura en Constantino Cavafis, el helenista de Alejandría, reencarnación a su vez de Calímaco, el poeta griego de los siglos IV-III a. de C., las sucias yacijas del comercio carnal son "el tálamo de Ítaca"; en suma, una "gestión de simulacros" que es toda versión poética de la realidad.

Descrédito del héroe supuso la superación del realismo como fórmula estética. Liberado del esquemático concepto de que la poesía había de contribuir al final de la dictadura de Franco y para ello debía ser capaz de comunicar con el pueblo mediante un lenguaje directo y denotativo, Caballero Bonald buscó por sí mismo en la experimentación de las capacidades expresivas del lenguaje y en el bagaje mítico-legendario de la cultura grecolatina que tan bien conocía la vía para destacar las contradicciones y sevicias de la realidad bajo el franquismo y sus secuelas. Y enfrentarse a ellas desde la belleza de la creación artística. De esta manera la presencia de referencias mitológicas se incrementó notablemente en su obra.

Ya en el primer poema del libro, "Hilo de Ariadna", encontramos la presencia de episodios mitológicos como referentes metafóricos de experiencias vitales. La aventura en Cuba con una cantante llamada Hortensia se combina con la historia de Ariadna, hija de Minos y Pasífae, reyes de Creta, quien ayudó a Teseo a salir del laberinto y luego fue abandonada por él en la playa de Naxos. El mismo rey Minos y la laguna Estigia aparecen en el poema en forma de prosa "Segundo círculo". El río Leteo, uno de los del Hades, cuyas aguas producían el olvido completo de lo vivido antes de la reencarnación de las almas según la mitología griega, es citado en "Guárdate de Leteo" porque no se quiere olvidar una visita al barrio prostibulario de Copenhague, cuyo recuerdo "me defenderá / contra la sordidez de la virtud" (Caballero Bonald, 2011: 306). "Diosa en el Ponto 
Euxino" es un poema de homenaje a Ovidio a propósito de otro viaje, esta vez a Rumanía, donde visitó Constanza, la Tomis romana donde sufrió exilio a orillas del Mar Negro el autor de las Metamorfosis. Los restos de una antigua estatua le evocan el tiempo clásico y a la bailarina gaditana Telethusa, cantada por Marcial.

El "Apócrifo de la Antología Palatina" (Caballero Bonald, 2011: 334) es un magnífico ejemplo de cómo José Manuel Caballero Bonald integra las referencias mitológicas en su universo poético personal. Se trata de una imitación de los textos poéticos griegos compilados definitivamente en la Constantinopla del año 917 por Constantino Céfalas, en la que de nuevo una escena de burdel sevillano donde el protagonista del episodio goza de la "olímpica ansiedad" de una boca es emparentada con la mitología, si bien por vía de negación: "cuando quien esto escribe / amaba impunemente no en el templo / de Afrodita en Corinto, / sino en la clandestina alcoba bética". Aunque el plano referencial mítico es recuperado de inmediato para crear una mitología propia que desarrollará a partir de entonces en su obra poética: "donde oficiaba de suprema hetaira / la gran madre de héroes, fugitiva / del Hades y ayer mismo / vendida como esclava / en el impío puerto de Algeciras".

La figura de esta esclava reaparecerá con frecuencia en sus textos vinculada a la muchacha Manuela Cipriani, prostituta creadora de una estirpe en su novela Ágata ojo de gato (1974), escrita coetáneamente a muchos de los poemas de este libro. La novela se desarrolla en el Coto de Doñana, convertido en un territorio mítico-legendario denominado Argónida por Caballero Bonald como universo narrativo propio, a cuyo origen como fruto de un espejismo infantil se refiere el poema "Argónida, 13 de agosto", que acaba como el poema "Cloto" de Las horas muertas: "sigue siendo verdad lo que aún no conozco?" (Caballero Bonald, 2011: 337). El término compuesto Argónida es un feliz hallazgo, pues evoca en su primer elemento a los muchos Argos de la mitología griega recordemos a los argonautas que acompañan a Jasón en la búsqueda del Vellocino de Oro, y con el sufijo ónida perfecciona una intuitiva significación de reino 
mitológico o arcaico.

El poema "Navegante solitario" (Caballero Bonald, 2011: 311) se refiere a ese legendario territorio junto a aquellas "últimas columnas de la mar" referencia muy evidente a las de Hércules, donde se habría refugiado Licurgo, el legendario legislador de Esparta, "oriundo de las estribaciones del Taigeto", en busca de armonía y justicia. La mención "indicios de culturas magníficas" abunda en la supuesta existencia de la perdida capital del histórico reino de Tartessos en el estuario del Guadalquivir, en la actualidad ocupado por la superficie de Doñana, teoría recurrente en el imaginario de algunos eruditos locales.

En el poema que da título al libro, "Descrédito del héroe", la fabulación mítico-legendaria incluye "el falso obispo de Argónida" y recupera el episodio troyano de la incineración de Patroclo ("arrojado al fuego en unión de su escudo"), que ya había evocado en otro poema, "La otra cólera de Aquiles", monólogo dramático de Aquiles su desesperado amante. Pero ahora se trata de un nuevo procedimiento de ironía mitificadora, pues sirve para referirse a la muerte del dictador Francisco Franco, fallecido tras un lento proceso de descomposición orgánica descrito con detalles en los comunicados de su equipo médico. Ningún español de aquel tiempo podía leer en otra clave las líneas finales: "esa nauseabunda opción a la inmortalidad que se alberga en los excrementos del héroe" (Caballero Bonald, 2011: 321).

En “Técnica de la imaginación” reaparece "esa gran madre lujosa y multípara, vendida como esclava al investido de poderes", que ya conocemos del poema "Apócrifo vestido de poderestrias de Ulises experiencia mallorquina con referencias $m$ de la antología Palatina", aunque es un texto donde el poeta exhibe su capacidad para ambientar su experiencia mallorquina con referencias mítico-legendarias de carácter geográfico, histórico, literario o simplemente ambiental: Damasco, “olor a papiro y a remo de Esmirna”, jeroglífico, "Artajerjes Longímano, disfrazado de alquimista de Cefalonia, escuchó son complacencia demasiada las sanguinarias industrias de Ulises", "la naturaleza femenina de Homero", "púrpura y bronce fenicios", "harapiento taumaturgo que 
mora como un dios olvidado" (Caballero Bonald, 2011: 328-329).

Volvemos a encontrar a la legendaria esclava "bellísima harapienta que merodeaba por el mercado de Sanlúcar, tenía que ser sin duda la última portadora aborigen del talismán" en un texto de su siguiente libro Laberinto de Fortuna (1984), todo él compuesto por poemas en forma de prosa: "Super flumina Babylonis" donde se destaca la "edénica antigüedad del gran río", que dota de prestigio mítico al Guadalquivir, cuyo título toma el poeta del célebre Salmo 136. Remite sin duda al personaje Manuela Cipriani de Ágata ojo de gato, de quien en la novela se afirma: "la portadora-del-talismán tanteaba a ciegas en busca de un placer indiferenciado cuya posible consecución antecedía sin remedio al turno del hastío y la pavorosa impasibilidad con que aguardaba la aparición del espectro del normando" (Caballero Bonald, 1974: 127). Esta identificación se hará explícita muchos años después en Entreguerras (2012) al recordar el sustrato autobiográfico de la novela:

pupila de prostíbulo heroína de fábula fundadora de rios

Teresita o Manuela ya desde entonces convertida

en la última portadora aborigen del talismán

y devorada por fin por la insaciable justicia vengadora de la propia

[tierra.

(Caballero Bonald, 2012: 111)

El personaje de la muchacha legendaria reaparecerá también en el poema "Maldita flor efímera incolora como una lágrima" de Desaprendizajes: llega a la casa de la playa donde habita el poeta "como quien vuelve del riguroso mar de Ulises [...] ya no volvería a surgir del mar en calidad de diosa investida de poderes" (Caballero Bonald, 2015: 36).

El texto "Héroe epónimo de Argónida" (Descrédito del héroe) abunda en la ambientación legendaria de dioses y semidioses o semihéroes: la adivinación por escrutinio de las entrañas de las aves, la ceniza o el oráculo, Nínive, Babilonia, Tartessos, el errabundo invencible como Anteo, 
el hijo de Gea, de quien habría tomado el poeta el nombre de su universo narrativo. Sin embargo, en "Mientras tanto todavía" el héroe del que se hace descender la menesterosa comunidad residual que aún habita el Coto es Argantonio, único rey tartésico del que existen referencias históricas.

Esa mitología personal aflora en poemas del libro La noche no tiene paredes (2009), como "Árbol genealógico" y "Leyenda de la realidad", donde se refiere de nuevo a la "sagrada demarcación de Argónida" (Caballero Bonald, 2011: 709) con esa mitología personal creada/soñada por el poeta: la marinería, los toros mitológicos, etc., que convierte ese territorio geográfico en una leyenda. En "Jardín de las Hespérides" imagina el poeta de acuerdo con el geógrafo griego Estrabón que allí estaba el mítico jardín donde crecían las manzanas doradas que cuidaban las Hespérides, ninfas de los árboles frutales. Frutos que habría de robar Hércules en el undécimo de los trabajos. Precisamente en este es en el que venció al gigante Anteo, nuestro viejo conocido del libro de 1956. Entre las hespérides, Caballero Bonald sólo menciona a Aretusa, la que consagró su castidad a la diosa Artemisa.

Volverá sobre Argónida en el poema "Mater terra" de su libro Desaprendizajes (2015), donde contrasta el destino que han tenido las dos orillas de la desembocadura del Guadalquivir "bandas" en la terminología local: en la izquierda la especulativa depredación urbanística ha producido la degeneración física del terreno, evidenciada por la conservación excepcional de la orilla derecha, el Coto de Doñana, que él concibe como "mundo de arcaicas prerrogativas inviolables [...] el lugar donde creció el jardín de las hespérides permanece simbolizado en esa tierra madre argonidense, justo frente a la ventana de la casa en que ahora escribo" (Caballero Bonald, 2015: 47).

En su libro Diario de Argónida (1997), el poeta utiliza en el título el nombre mítico o como él lo define, "topónimo ficticio con que suelo referirme literariamente al Coto de Doñana" (Caballero Bonald, 2011: 531), aunque en realidad en estos poemas remite a "una concreta localización geográfica [...] un escenario preferentemente real" (Caballero Bonald, 2011: 53), el que contempla desde su casa de Montijo (Cádiz), 
cuyos olores, vientos y sonidos percibe en los diversos momentos del día y de la noche y ambientan sus reviviscencias, inquietudes o diatribas contra la persistente realidad sociopolítica. No obstante, pese a ese carácter de poemario inserto en la realidad vivida cotidianamente la mitología sigue estando presente. Tal vez porque en los años en que estos poemas fueron escritos Caballero Bonald acostumbraba navegar en un pequeño velero de su propiedad costeando los litorales gaditanos, en adelante se hace frecuente la presencia de relatos mitológicos y personajes relacionados con el mar y la navegación "pacté con Poseidón en favorables vísperas", afirmará en Entreguerras (Caballero Bonald, 2012: 109). Ya se ha citado a Ulises a propósito de poemas de Las horas muertas ("Cráter del tiempo") y Descrédito del héroe ("Técnica de la imaginación"), ahora en "Fábula" su figura es referente para la época de su propia vida recordada como:

\section{Tiempo}

de benévolas puertas entornadas, de hospitalarios cuerpos, de excitantes travesías fluviales y de fabulaciones

\section{Tiempo magnánimo}

compartido también con semidioses

errabundos y hombres de mar que alardeaban

del decoro taimado de los héroes

Qué ha quedado, oh Ulises, de esa vida?

(Caballero Bonald, 2011: 462)

Vuelve a aparecer Ulises como referente personal en "Nadie", poema del libro La noche no tiene paredes (2009). En "Nocturno con barcos" (Diario de Argónida) evoca las sirenas, que tanto fecundan la imaginación adolescente, y la historia de los argonautas, que vuelve a aparecer en "Mare tenebrosum" del libro Manual de infractores, poema que tiene mucho que ver con su experiencia marinera en las costas gaditanas, aunque se refiere 
a un navegante solitario que circunvala el mar sin descanso después de haber dado una primera vuelta al mundo en un velero. En "Sancti Petri" se refiere a los "vestigios de una historia / de almadraberos y suntuosas gentes / de la mar" (Caballero Bonald, 2011: 645), e invoca a Hermes "dios de los viajeros" para que proteja los restos arqueológicos de la costa de la depredación "de agrimensores y amanuenses / que acuden hasta aquí para malbaratar / los escombros postreros de la historia" (Caballero Bonald, 2011: 645). También el ya citado "Jardín de las Hespérides" tiene relación con experiencias náuticas en el entorno de la desembocadura del Guadalquivir

En Entreguerras narra en clave mítica e hiperbólica sus incursiones náuticas en las marismas del Guadalquivir, donde sostiene que existió la legendaria capital del reino tartesio:

navegué por las rutas insignes por los mismos trasmares de los argonautas goberné naves de espaciosas indistintas velas cóncavas naves tripuladas por desiguales héroes innombrados buscando en los adentros presuntos del lago Ligustino algún visible indicio conservado en mi memoria más predecesora y así fui conducido por los voltarios dioses del lugar más allá de la última frontera de los espejismos allí donde el luciferi fanum y las bien documentadas tumbas subacuáticas se nutren de despojos corporales llagas arqueológicas pecios de galeones.

(Caballero Bonald, 2012: 113)

$\mathrm{Si}$ en "Mare tenebrosum" se menciona a Poseidón, en Desaprendizajes el poema titulado "Idioma de Poseidón" es un emocionado tributo al mar y la navegación a vela, espacio de libertad personal para el poeta, aunque sujeto a normas estrictas cuya vulneración es castigada con la muerte. Allí leemos:

En el libro genealógico de los mareantes están documentadas las leyes que nadie nunca ha podido leer, pero que todos siempre 
han respetado por decisión soberana. Son leyes atávicas escritas en el idioma de los semidioses y conservadas en el interior de la espuma igual que se conserva la salamandra en el interior del fuego (Caballero Bonald, 2015: 26).

Además de los casos citados, en la obra poética de Caballero Bonald podemos encontrar otros textos de contenido mitológico. En Laberinto de Fortuna dos poemas: "Ninfa Egeria" y "Un brumoso día de Levante", sobre Tetis la ninfa del mar, madre de Aquiles. En Diario de Argónida "Caja de Pandora", que emplea como título esa expresión procedente del mito griego de la primera mujer hecha por Hefesto por mandato de Zeus, para expresar la sensación producida por el ruido de una bandada de milanos en las dunas "bullicio como de plegarias", que le recuerda un sonido de la oración de cientos de viajeros judíos en una sala del aeropuerto de San Luis (Misuri).

La huella mitológica es aún mayor en su libro La noche no tiene paredes (2009). A los ya mencionados se añade "Contra Casandra", donde se refuta la predicción del futuro don que Apolo habría concedido a la hija de Príamo y Hécuba, los reyes de Troya, según el mito griego ("líbrate / de profetas, videntes, sacerdotes") y la idea de predestinación ("Ni la vida es tan corta como pensó Casandra / ni está el mañana ni el ayer escrito", Caballero Bonald, 2011: 698). Rechazo a la videncia que se repite en "Frente al espejo, la afanosa máscara" con una mención general a los dioses ("Oh dioses despiadados / que ciegan con engaños al vidente" (Caballero Bonald, 2011: 707) a propósito de la dificultad de reconocer la propia imagen en el espejo por el paso de los años.

Entreguerras o De la naturaleza de las cosas (2012) es una magna autobiografía poética de casi tres mil versos en la que no podía faltar la presencia de la mitología y su importancia a lo largo de su trayectoria. Hay algunas referencias generales, como "los dioses más versados en crueldades" (Caballero Bonald, 2012: 42), "iluminadora voluntad del hosco inescrutable dios de la tinieblas" (Caballero Bonald, 2012: 43), "la 
nunca interrumpida recurrencia del mito" (Caballero Bonald, 2012: 73), "el instinto prenatal de la mitología" (Caballero Bonald, 2012: 110), o la confesión de cómo las narraciones mitológica le sirvieron de niño para suplir en su espíritu el relato doctrinario mucho más siniestro y amenazador de la España oficial:

así el culto a las deidades que en la naturaleza tratan de conspirar genera como el reemplazo de algún vislumbre instintivo de fe una variante elemental pueril de panteísmo (repetías).

(Caballero Bonald, 2012: 156)

Al tratarse de una autobiografía, tan importantes son los recuerdos como los olvidos, equilibrio presente siempre en su imaginario poético. Aquel Leteo contra el que le vimos antes advertir en un poema de Descrédito del héroe reaparece al recordar su retorno "a las infancias todas al locus amoenus al milenario arcano del río del olvido" (Caballero Bonald, 2012:115); aunque tiene mucha mayor presencia la memoria, personificada en la mitología griega en la titánide Mnemosine, hija de Gea y Urano y madre de las musas, a quienes engendró con Zeus en nueve noches consecutivas. Caballero Bonald le rinde homenaje por su "tenaz desazonante convivencia":

Mnemosine la tantas veces nobilísima impartidora de quimeras la libre otorgadora de dones aleatorios de cóleras de asombrosos de [consuelos la fedataria inmemorial de todo lo que un día revertí a las fijezas afectivas.

(Caballero Bonald, 2012: 193)

Con ese proceso mitologizador de la realidad tiene mucho que ver el poema "Euménide" de La noche no tiene paredes, que relata la visita al poeta de una de las diosas de la venganza ("Dijo pertenecer a las Euménides y ser oriunda de Sanlúcar”), quien le habría inoculado una locura transformada en ira retrospectiva. Interesa comprobar que el poeta 
adjudica un sentimiento tan íntimo y personal mediante su trasposición a los efectos de la acción de los dioses, como en la mitología griega. El inicio del poema nos ofrece una interesante explicación metapoética:

Con posterioridad a esos intempestivos trabajos atribuidos a Hércules, cuando ningún síntoma hacía prever el incremento de mitologías en los [derramaderos de la realidad, vino aquella locura a llamar a mi puerta.

(Caballero Bonald, 2011: 724)

También en Desaprendizajes (2015), de nuevo un libro de poemas en forma de prosa, aparece la mitología. "Erígone" trata del personaje mitológico de ese nombre, hija de Egisto y Clitemnestra, reyes de Micenas, que tuvo un hijo de su hermanastro Orestes, quien trató de asesinarla, pero fue rescatada por la diosa Artemisa. Caballero Bonald parece tener predilección por las jóvenes que, siendo inocentes, parecen víctimas de un destino aciago y de la codicia de héroes y dioses en los relatos mitológicos: "Hermosa y preterida, aciaga portadora de un estigma letal, fue relegada a los ámbitos palaciegos subalternos y se exilió a sí misma de las concurrencias amables de la vida" (Caballero Bonald, 2015:54). Despojada, pues, del carácter divino ¿expulsada del paraíso? la muchacha representa la historia de la postergación de la mujer, historia de castigo, sometimiento y sufrimiento, pese a su condición de creadora de estirpes, desde el inicio de las sociedades agrícolas, que intenta explicar la construcción de relatos mitológicos.

$$
* * *
$$

El cotejo minucioso de la obra poética de Caballero Bonald en relación con los mitos clásicos permite concluir que es abundante y continuada, pudiendo descartarse que se trate de una opción culturalista propia de una moda estética coyuntural. Las referencias míticas, sean al 
mito en sí o a alguno de sus personajes, están presentes prácticamente en todos sus libros salvo en el primero, Las adivinaciones (1952) y el quinto, Pliegos de cordel (1963) a lo largo de más de seis décadas, lo que demuestra, por el contrario, que se trata de una huella indeleble en su formación intelectual, en su imaginario cultural y en la concepción narrativa (en prosa o en verso) de su universo personal.

Las razones de que esto sea así entran en el ámbito de la especulación, pero no deben alejarse de la naturaleza de los mismos relatos mitológicos, su mutabilidad según los autores que los transmiten, su polisemia y su capacidad de renovación en el paso de la cultura griega a la latina. En todo caso, muy alejados de la fijación canónica establecida por las religiones monoteístas, las religiones "del Libro", cuyo código punitivo estricto, más cercano a lo jurídico que a lo moral, era desconocido en el politeísmo olímpico. Los dioses griegos se comportan como seres humanos y los héroes se acercan a los dioses en una convivencia mucho más estimulante para el temperamento del poeta que la rígida compartimentación entre Dios y los hombres o mujeres que consolidan la religión cristiana o la musulmana, por ejemplo. Los dioses, semidioses y héroes de la mitología se engañan, roban, asesinan, cometen parricidios, secuestros, adulterios, incestos, estupros, etc., lo que les hace sumamente atractivos "fieramente humanos", dirían Góngora y Blas de Otero para un espíritu que desdeña la templanza como virtud y desconfía del virtuoso, que aborrece el dogmatismo y la intransigencia, que rechaza cualquier rigorismo inquisitorial y la hipocresía de quienes se sienten en posesión de la verdad y gestionan en provecho propio el misterio de la espiritualidad y la angustiosa aspiración a una ultraterrena vida eterna. Contra ellos opone "ese proteico irreductible arbitrio de la preponderancia de la libertad" (Caballero Bonald, 2012: 153), al que tan bien se acomodan los relatos mitológicos.

Caballero Bonald no añora como su admirado amigo Luis Cernuda el tiempo en que la existencia de los hombres y los fenómenos de la naturaleza eran explicados por medio de los relatos mitológicos, pero sí encuentra en estos una fórmula narrativa adecuada para expresar una 
vida larga como la suya, con numerosos episodios caracterizados por la contradicción y la desmesura, impulsada por las pasiones y la rebeldía, insumisa a los cánones sociales y a las prescripciones del poder, siempre leal solo a sus convicciones, seguramente digna de uno de esos relatos en que los dioses se muestran a imagen y semejanza de los hombres y no al revés. O quizás porque, como afirma en Entreguerras, desde la infancia la afición a los dioses mitológicos venía a compensar la incapacidad de creer en las doctrinas religiosas que pretendían imponérsele en la sociedad dominada por el clericalismo franquista.

Tal vez por eso, no duda en utilizar personajes como Ulises, Narciso, Anteo, Hércules, Aquiles, Patroclo, Cloto, Ariadna, etc., como referentes de sus propias experiencias. Pero da un paso más y llega a crear un mito propio, la fundación de Argónida, integrado en el conjunto de la mitología clásica, pues allí se ubicaría el jardín de las Hespérides, para sustentar su universo narrativo, elevando su escenario geográfico más querido, la desembocadura del Guadalquivir y su entorno, el antiguo estuario, a rango de región mítica. No cabe duda de que ningún otro poeta español de su tiempo puede disputar a Caballero Bonald la preeminencia en el vínculo predilecto de su obra con la mitología clásica.

\section{REFERENCIAS BIBLIOGRÁFICAS}

AGUIRRE MARTÍNEZ, G. (2015). "Perspectiva del mito clásico en la poesía de José Ángel Valente". En Humanismo y pervivencia del mundo clásico. V. Homenaje al profesor Juan Gil, J. M. Maestre Maestre, S. I. Ramos Maldonado, M. A. Díaz Gito, M. V. Pérez Custodio, B. Pozuelo Calero y A. Serrano Cueto (eds.), 2363-2368. Madrid: Instituto de Estudios Humanísticos.

ANDÚJAR ALMANSA, J. (2000). "Memoria, mito y laberinto en Descrédito del héroe, de J. M. Caballero Bonald”. Dicenda. Cuadernos de Filología Hispánica 18, 51-60. 
ARCAZ POZO, J. L. (2010). "Presencia de los mitos clásicos en la poesía de los “posnovísimos"”. En Mitos clásicos en la literatura española e hispanoamericana del siglo XX, J. A. López Férez (coord.), vol. I, 397-425. Madrid: Ediciones Clásicas.

CABAllero BONALD, J. M. (1974). Ágata ojo de gato. Barcelona: Seix Barral.

(2011). Somos el tiempo que nos queda. Obra poética completa (1952-2009). Barcelona: Seix Barral.

(2012). Entreguerras. Barcelona: Seix Barral.

(2015). Desaprendizajes. Barcelona: Seix Barral.

CAMACHO CUENCA, S. (2009). "Nuevos contextos del mito de Ulises en la poesía española contemporánea”. En Héroes, mitos y monstruos en la literatura española contemporánea, Fidel López Criado (coord.), 297-308. A Coruña: Andavira.

COSSÍO, J. M. (1952). Fábulas mitológicas en España. Madrid: Espasa Calpe.

CRISTÓBAL, V. (2000). "Mitología clásica en la literatura española: consideraciones generales y bibliografía". Cuadernos de Filología Clásica. Estudios Latinos 18, 29-76.

DÍAZ DE REVENGA, F. J. (2003). La tradición áurea. Madrid: Biblioteca Nueva.

FERNÁNDEZ LÓPEZ, J. y MORA DE FRUTOS, R. (2004). "Las dos caras de Orfeo en la poesía española reciente: Guillermo Carnero y Antonio Colinas". Anuario de Estudios Filológicos 27, 101-119. GONZÁLEZ DELGADO, R. (2005). "Penélope y el secreto de una espera. La pervivencia de una heroína griega en la poesía contemporánea". En Venus sin espejo: imágenes de mujeres en la antigüedad clásica y el cristianismo primitivo, M. González González y M. A. Pedregal Rodríguez (eds.), 327-345. Oviedo: KRK ediciones.

LACALLE CIORDIA, M. A. (2005). "La influencia de la antigüedad clásica en la poética de José Angel Valente". Cuadernos del Marqués de San Adrián: Revista de Humanidades 3, 43-91. 
LANZ, J. J. (2011). Nuevos y novísimos poetas en la estela del 68. Sevilla: Renacimiento.

LÓPEZ FÉREZ, J. A. (coord.) (2010). Mitos clásicos en la literatura española e hispanoamericana del siglo XX. Madrid: Ediciones Clásicas, 2 vols.

LUJÁN ATIENZA, Á. L. (2009). "El mito de Narciso en la poesía española contemporánea”. En Héroes, mitos y monstruos en la literatura española contemporánea, Fidel López Criado (coord.), 323-330. A Coruña: Andavira.

MÁRQUEZ, M. Á. (1994). “Afrodita y Narciso”. En Las formas del mito en las literaturas hispánicas del siglo XX, Luis Gómez Canseco (ed.), 135-151. Huelva: Universidad de Huelva.

MARINA SÁEZ, R. M. (2001-2003). "Penélope, Ulises y la Odisea en la poesía española contemporánea escrita por mujeres”. Tropelías 12-14, 271-284.

MERINO MADRID, A. (2015). La mitología clásica como instrumento para la construcción de una nueva identidad de género en la poesía española del siglo XX escrita por mujeres. Tesis doctoral dirigida por Juan Antonio López Férez y Rosa María Pedrero Sancho, UNED.

MORALEJO ÁLVAREZ, J. J. (2010). “Influencia de los mitos clásicos en los poetas Novísimos”. En Mitos clásicos en la literatura española e hispanoamericana del siglo XX, J. A. López Férez (coord.), vol. I, 365-395. Madrid: Ediciones Clásicas.

NEIRA, J. (2003). "Gongorismo y vanguardia en Rafael Alberti: Las metamorfosis iconoclastas de Cal y canto". En Aire del sur buscado. Estudios sobre Luis Cernuda y Rafael Alberti, F. J. Díez de Revenga y M. de Paco de Moya (coords.), 269-291. Murcia: Fundación Caja Murcia.

(2014). Memorial de disidencias. Vida y obra de José Manuel Caballero Bonald. Sevilla: Fundación José Manuel Lara.

ORTEGA GARRIDO, A. (2011). "El nacimiento de Venus en poetas 
españoles de vanguardia”. Espéculo. Revista de Estudios Literarios 47. Disponible en línea: http://pendientedemigracion.ucm.es/info/ especulo/numero47/nacvenus.html [06/06/2018].

PAYERAS GRAU, M. a (2009). "La odisea de Penélope. Lecturas de la mitología clásica en la poesía femenina española contemporánea”. En Héroes, mitos y monstruos en la literatura española contemporánea, Fidel López Criado (coord.), 281-288. A Coruña: Andavira.

PUJALS GESALI, E. y RODRÍGUEZ. DE LA FLOR, F. (1981). "Un aspecto de la poesía de Antonio Colinas: lo mítico". Ínsula 36, 3.

PUPPO, M. L. (2006). "Destino de Ícaro: presencia de un mito clásico en la poesía de Aníbal Núñez”. Cuadernos de Filología Clásica. Estudios Latinos 26.1, 173-180.

RUIZ ESTEBAN, Y. (1990), El mito de Narciso en la literatura española. Madrid: Universidad Complutense de Madrid.

SALGADO, M. (2009). "Figuras del héroe y construcción del mito en la obra de Aníbal Núñez. Estampas de ultramar". En Héroes, mitos y monstruos en la literatura española contemporánea, F. López Criado (coord.), 135-142. A Coruña: Andavira.

Recibido el 27 de abril de 2018.

Aceptado el 8 de junio de 2018. 
